\title{
The Liver and Intestinal Research Centre: Bridging clinical research and community practice
}

\author{
Frank Anderson MD¹, Paul C Adams MD², Editor-in Chief
}

$D^{\prime}$ Frank Anderson is a gastroenterologist and Associate Professor Emeritus at the University of British Columbia (UBC) in Vancouver, British Columbia. Because of mandatory retirement at the Vancouver General Hospital and UBC, Dr Anderson established the Liver And Intestinal Research (LAIR) Centre, (www.laircentre.com), a private research facility six years ago, to continue clinical investigations in liver disease and inflammatory bowel disease.

PA: Can you tell us what led up to the development of the LAIR Centre?

FA: At the time of my mandatory retirement, neither the Hospital administration nor the Division of Gastroenterology had the mechanism or personnel to take over the many clinical trials I was overseeing. I was supporting a staff of eight and the Hospital and University were not prepared to take over the staff either.

PA: Are there differences between a private research facility and university and hospital facilities?

FA: The major differences are the lack of university and hospital bureaucracy, the university institutional review boards and lawyers who are so inefficient, and our ability to initiate studies quickly, often months ahead of university divisions.

PA: Is it a fundamental concept of the LAIR Centre that overheads from pharmaceutical research studies can be redirected back into your facility for personnel, office space, endoscopy equipment, etc, instead of being sequestered by universities that demand increasing percentages and in many cases deliver substandard facilities?

FA: Definitely. There is no hesitation by the pharmaceutical companies in paying start-up fees, overhead and administrative costs, and all other reasonable costs. Another advantage is that for many studies, we use a central ethics board and approval is obtained by the pharmaceutical company, and all that the LAIR Centre has to do is send the regulatory documents. This means that we can obtain ethics approval in a matter of weeks rather than months.
PA: Is the LAIR Centre only performing research studies or is it a hybrid of research studies and private practice? Is the hybrid model a feasible way to fund an ambulatory endoscopy centre that also performs screening colonoscopy?

FA: I still maintain a large clinical practice at the LAIR Centre and this supplies many patients for the clinical trials. My four nurses are involved in managing patients in the clinic and are familiar with the patients and are able to assist in identifying patients who are suitable for clinical trials. Research funds cover equipment costs including computers, electrocardiogram machines and endoscopy equipment.

PA: Can you tell us some of the details of the LAIR Centre?

FA: The LAIR Centre has 11 full-time and three part-time staff: four nurses, a research assistant, a receptionist, a clinical trials administrator, a clinical and IT support person, a business manager, a physician, a part-time dietitian, a part-time counsellor, a part-time psychologist and a part-time payroll officer. We have 3500 square feet of space, with an endoscopy room (Figure 1), a recovery area, an infusion room, separate work stations for each nurse, four interview rooms (Figure 2), two physician offices with examining rooms, a laboratory, kitchen and waiting room. We are currently performing more than 24 clinical trials. We collect all blood samples in-house, process all samples, perform electrocardiograms and now have a transient ultrasound elastography machine.

PA: Are there similar centres operating in Canada?

FA: I am not aware of a similar facility in gastroenterology. The LAIR Centre is a private nonprofit research society and foundation. We function as a real team and everyone feels part of LAIR and completely involved. We have regular research and business meetings, and everyone is involved in planning.

PA: Does the LAIR Centre appeal to pharmaceutical companies?

FA: The LAIR Centre is very appealing to pharmaceutical companies. Using private ethics boards, which often have a

${ }^{1}$ The Liver and Intestinal Research Centre, Vancouver, British Columbia; ${ }^{2}$ University Hospital, London, Ontario

Correspondence and reprints: Dr Frank Anderson, Liver and Intestinal Research Centre, Fairmont Medical Building, Suite 305, 750 West

Broadway, Vancouver, British Columbia V5Z 1H2. Telephone 604-876-5122, fax 604-484-3026, e-mail reception@LAIRcentre.com

Received and accepted for publication May 24, 2008 


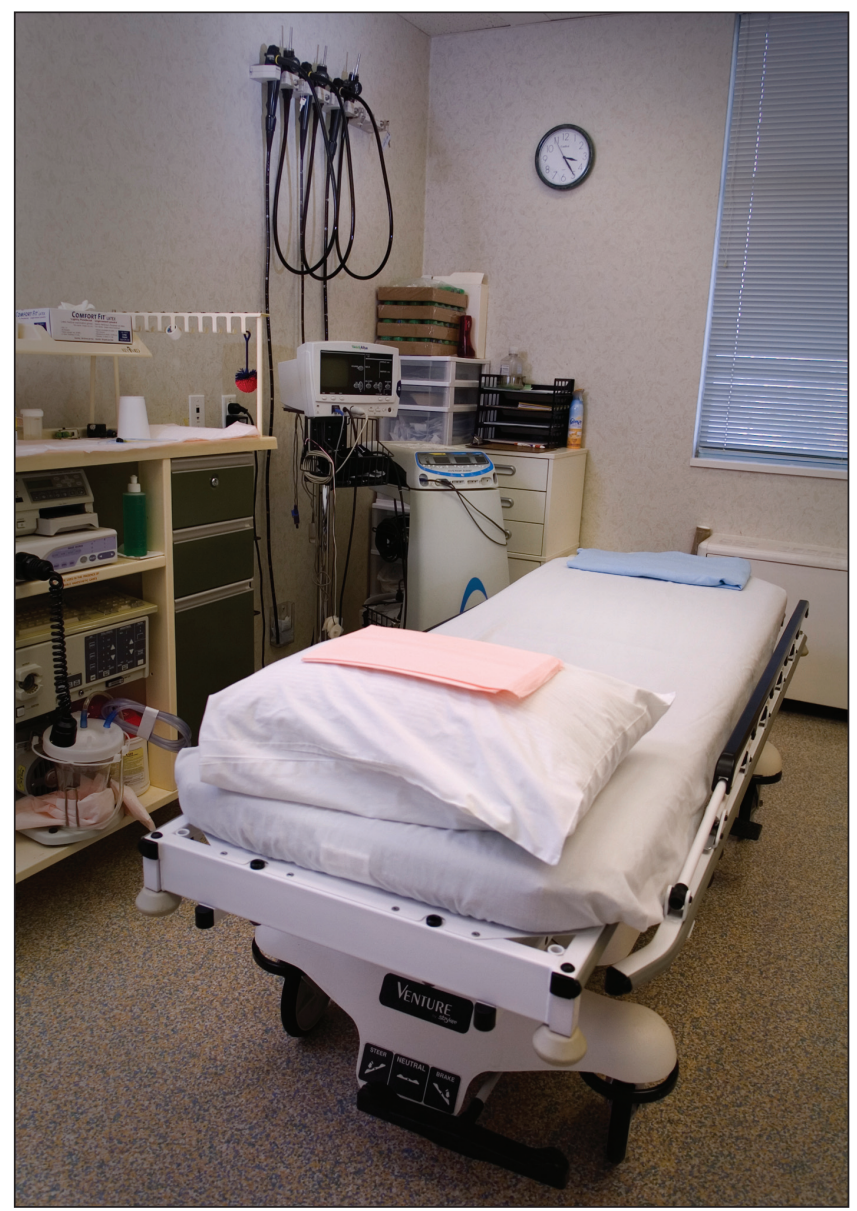

Figure 1) Endoscopy suite at the Liver and Intestinal Research Centre

better record than university institutional review boards, I can obtain ethics approval in three weeks. Thus, I can initiate a study in six to eight weeks and am often the first in the country, and sometimes in the world, to screen and enroll patients. Study monitors tell me that they love coming to our site because everything is so well organized and everything is in one place.

PA: Does the concept appeal to patients?

FA: Patients seem to be very appreciative of the LAIR Centre. Many patients tell us that they believe we are a real team and that they also feel part of the team. They appreciate interacting with all the members of our team and tell us that we are much more personable than the University. Because we are known as a research centre, most patients expect that we will be at the forefront of new research and also new treatments. Patients also believe that they are all important individuals and not just numbers in clinical trials as some have perceived when participating in studies at other centres.

PA: Does the LAIR Centre appeal to physicians in practice?

FA: The LAIR Centre is well received. We have a newsletter, called 'The Hepatitis Knowledge Network' mailed out to more than 900 physicians in British Columbia and the United States. We conduct a two-day mentorship program in hepatitis for physicians two or three times a year. We have a mentorship program

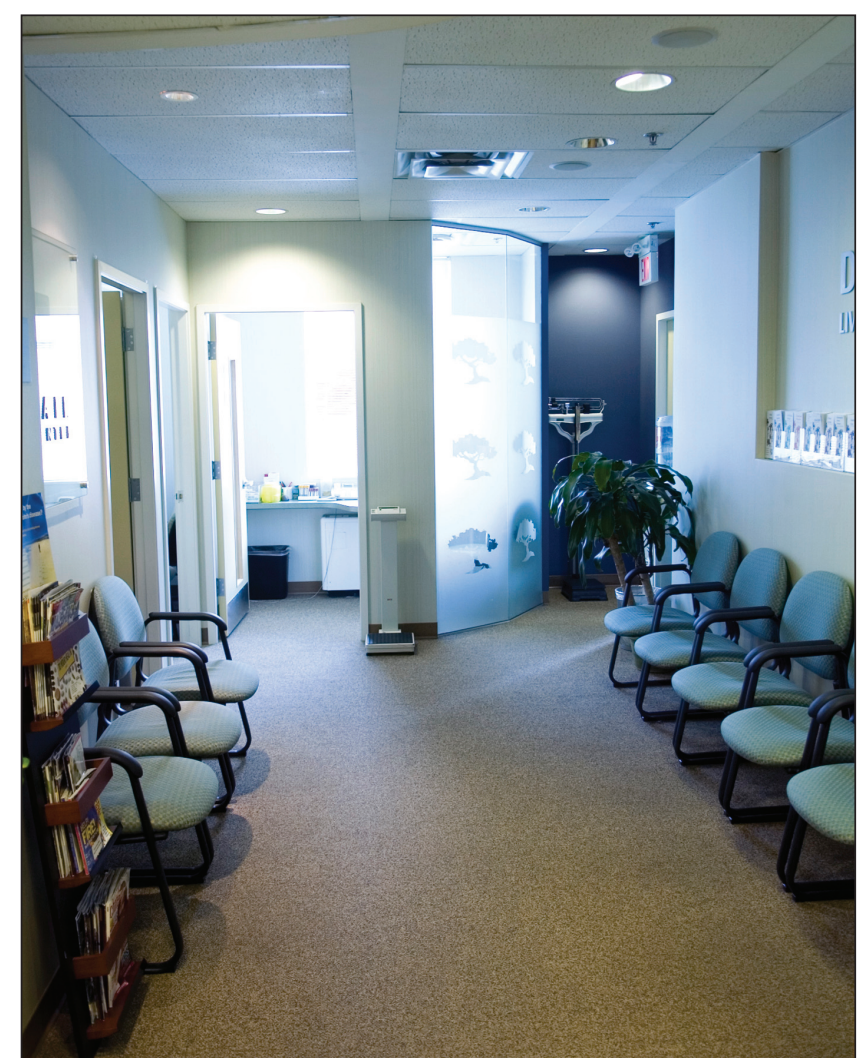

Figure 2) Waiting room and interview rooms at the Liver and Intestinal Research Centre

for nurses, and we are a training site for research technicians at the $\mathrm{BC}$ Institute of Technology as well as for people training as medical office assistants in local colleges.

PA: Are these centres a threat to the university model of clinical research?

FA: The major threat is that studies can be initiated quickly, there is much less bureaucracy to delay and hinder studies, and we can set our own hours and accommodate studies that require extra time such as drug and viral kinetic studies. Because of our unified approach, we can be much more efficient.

PA: What advice would you give to an entrepreneurial gastroenterologist who is considering a similar structure?

FA: Anyone interested is welcome to communicate with me. I am very willing to explain how the LAIR Centre works in detail. Such a person should know the atmosphere where he or she plans to work and what local resistance they may encounter, as well as what support there may be, particularly from referring physicians. The approval process by the College of Physicians and Surgeons for a nonhospital medical/surgical facility is very detailed, but very helpful. There are many requirements that the physician should be aware of. The regulations are not onerous and I believe set a higher standard than regulations that exist at a university or hospital. I believe that this is good and our policies and standard operating procedures are better than anything I experienced at the University or Hospital. We have a benefits package for all employees and are now starting a group registered retirement savings package for all employees. 


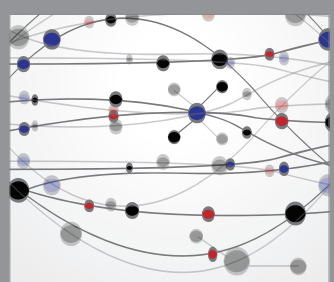

The Scientific World Journal
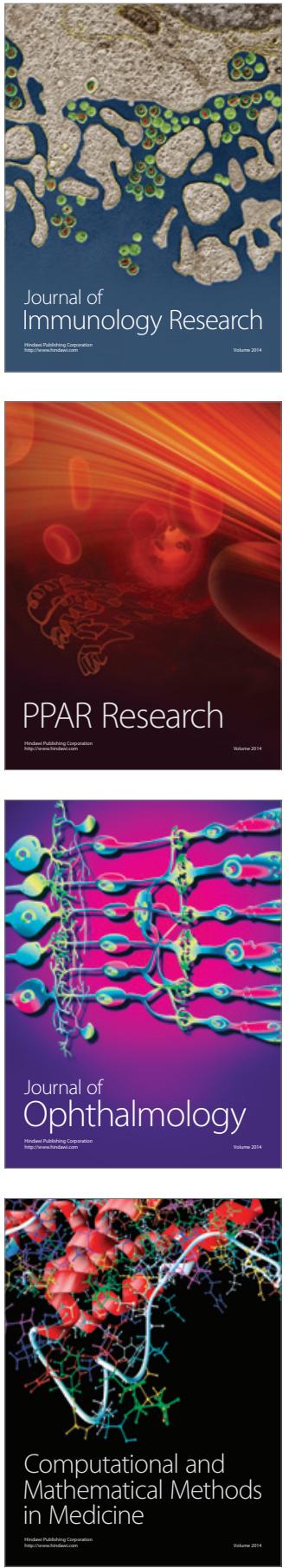

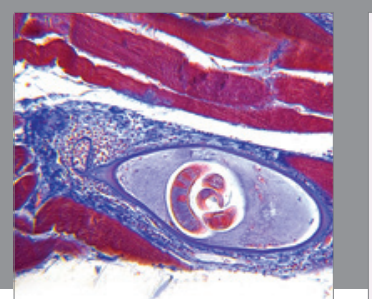

Gastroenterology Research and Practice

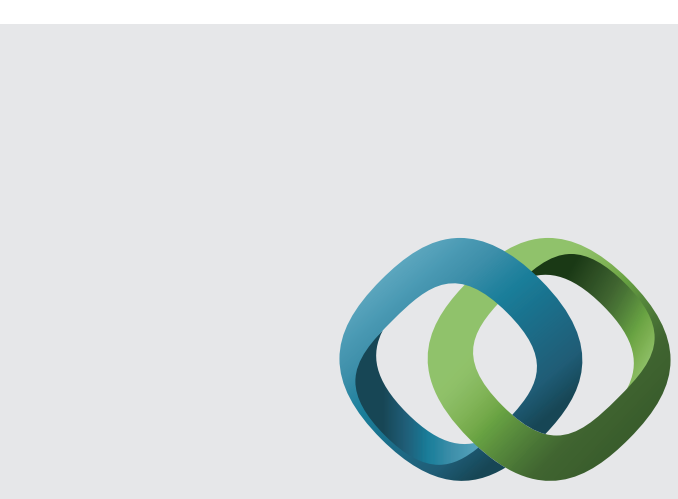

\section{Hindawi}

Submit your manuscripts at

http://www.hindawi.com
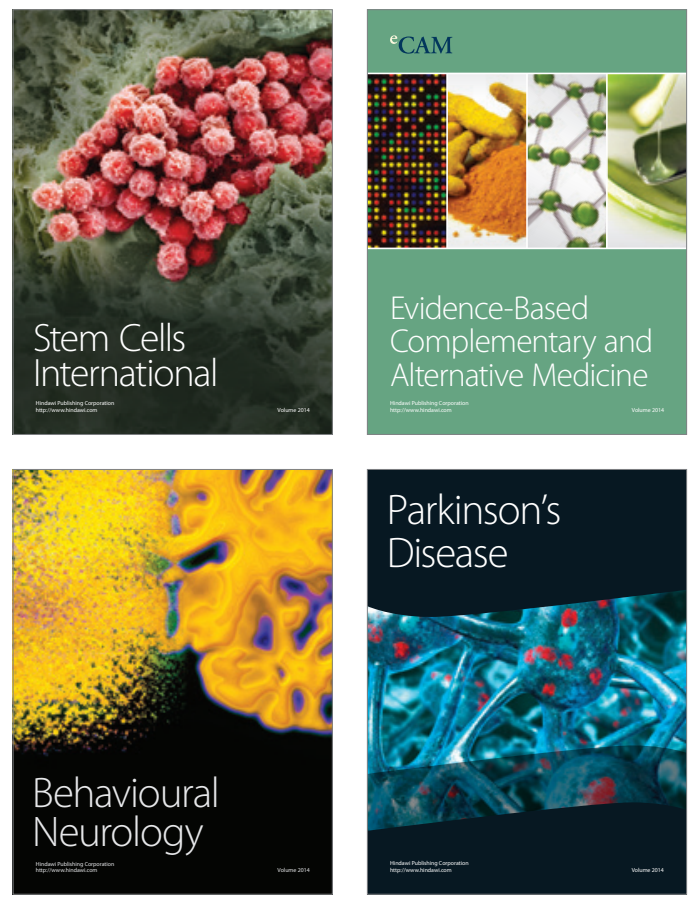
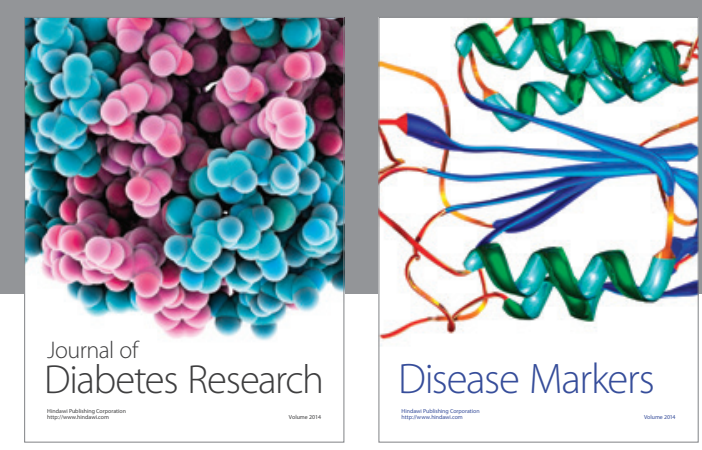

Disease Markers
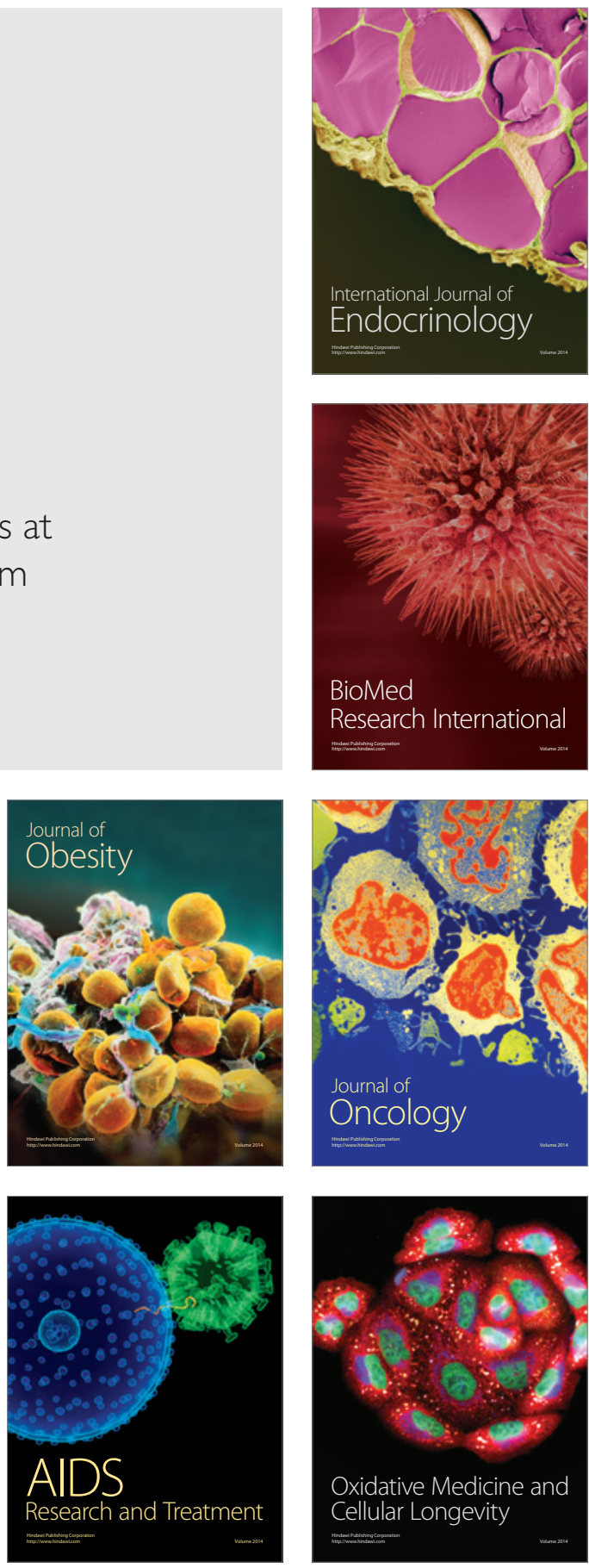